\title{
Cancer Therapeutic Procedure
}

National Cancer Institute

\section{Source}

National Cancer Institute. Cancer Therapeutic Procedure. NCI Thesaurus. Code C16212.

Any intervention for management of a malignant neoplasm. 